\title{
Quem vai à Igreja? Um Teste de Regressão Logística Ordenada do Modelo de Azzi-Ehrenberg para o Brasil
}

\author{
Lívio Luiz Soares de Oliveira \\ Pesquisador - Fundação de Economia e Estatística Siegfried Emanuel Heuser (FEE) \\ Endereço para contato: Rua Duque de Caxias, 1691 - Porto Alegre - RS \\ CEP: 90010-283 - E-mail: livio@fee.tche.br
}

Renan Xavier Cortes

Estatístico - Fundação de Economia e Estatística Siegfried Emanuel Heuser (FEE)

Endereço para contato: Rua Duque de Caxias, 1691 - Porto Alegre - RS

CEP: 90010-283 - E-mail: renan@fee.tche.br

\section{Giácomo Balbinotto Neto}

Doutor em Economia - Universidade Federal do Rio Grande do Sul (UFRGS)

Endereço para contato: Av. João Pessoa, 52, sala 18-B - Porto Alegre - RS

CEP: 90040-000 - E-mail: giacomo.balbinotto@ufrgs.br

Recebido em 12 de janeiro de 2012. Aceito em 17 de dezembro de 2012.

\section{Resumo}

O moderno marco inicial da Economia da Religião é o modelo de Azzi e Ehrenberg (1975). Este modelo gerou diversos trabalhos empíricos vistando testar suas hipóteses. Neste artigo, testam-se as hipóteses do modelo de Azzi e Ehrenberg, aplicando-se um modelo de regressão logística ordenada, com dados da Pesquisa Social Brasileira (PESB) de 2004, sobre frequência religiosa. De acordo com os resultados obtidos, indivíduos do sexo feminino tendem a frequentar mais serviços religiosos: além disso, a frequência religiosa apresentou aumento com a idade e verificou-se uma correlação negativa com a renda.

\section{Palavras-Chave}

Economia da Religião, frequência religiosa, modelo de Azzi e Ehrenberg

\begin{abstract}
The modern landmark for the Economics of Religion is the model proposed by Azzi and Ehrenberg in 1975 to religious frequency. This model has several empirical studies in the literature in order to test their hypotheses. In this article, we test the hypothesis of the model of Azzi and Ehrenberg applying an ordered logistic regression with survey data of the Brazilian Social Research (PESB) 2004 on religious attendance. According to our results, women tend to attend more religious services; religious frequency showed an increase with age and is negatively correlated with income.
\end{abstract}

\section{Keywords}

Economics of Religion, religious attendance, Azzi and Ehrenberg Model

\section{JEL Classification}

Z12 


\section{Introdução}

O fato de, aproximadamente, $90 \%$ da população mundial, em 2010, possuir filiação religiosa, segundo dados da Association of Religion Data Archives (ARDA), ${ }^{1}$ constitui uma justificativa importante para o estudo da Economia da Religião e das implicações dela derivadas, pois isso indica que as religiões fornecem bens e serviços desejados e valiosos para a maioria das pessoas. Trabalhos recentes têm mostrado que a religiosidade está associada ao crescimento/desenvolvimento econômico (Barro e Mccleary, 2003), à fecundidade (Berman, Iannaccone e Ragusa, 2012) e à acumulação de capital humano no Brasil (Anuatti-Neto e Narita, 2004).

O modelo de Azzi e Ehrenberg (1975) retoma a discussão iniciada por Adam Smith $(1996,2004)$ duzentos anos antes sobre o mercado religioso. A partir do modelo de Azzi e Ehrenberg, o longo silêncio da Ciência Econômica sobre o comportamento religioso terminou, passando a existir, a partir daí, um crescente número de trabalhos buscando estudar a religião sob uma perspectiva econômica. $\mathrm{O}$ trabalho de Azzi e Ehrenberg, por isso, constitui-se em um verdadeiro marco refundador da disciplina. Conforme observam os autores desse estudo, todos os modelos de alocação doméstica do tempo pressupõem que o fluxo esperado de benefícios termina com a morte do indivíduo. No entanto, para um modelo de participação religiosa isso seria inapropriado, já que a grande maioria das religiões promete alguma espécie de vida ou recompensa após a morte. Também deveria ser considerado o fato de que os indivíduos religiosos veem os benefícios esperados do período pós-vida como estando intrinsecamente relacionados à sua alocação de tempo no presente. Dessa forma, a alocação de tempo para atividades religiosas deveria ser analisada dentro de um contexto de um modelo multiperíodo de alocação temporal, o que iria permitir aos indivíduos a obtenção de benefícios no período pós-vida.

Azzi e Ehrenberg (1975) propõem um modelo de maximização de utilidade multiperíodo para descrever os determinantes do comportamento religioso incluindo a divisão de participação entre marido e mulher, além do perfil de participação religiosa em seu ciclo de vida.

1 Dados obtidos em http://www.thearda.com/internationalData/regions/profiles/Region_23_1.asp (acesso em 10/01/2013). 
Os autores descrevem variações nas taxas de frequência a igrejas ao longo do tempo e entre indivíduos em determinados lugares.

Os testes foram realizados usando modelos multivariados e dados estaduais, para os EUA, de taxas de participação religiosa para os anos de 1926, 1936 e 1952, bem como dados de frequência religiosa para adultos no ano de 1973. A pesquisa procurou analisar a alocação do tempo para atividades religiosas, tomando as crenças como sendo predeterminadas. Os autores fazem questão de observar que os dados estatísticos coletados das igrejas não têm muita qualidade, porque o critério utilizado para se definir o que é um membro varia entre as diferentes igrejas e denominações, além de os próprios membros muitas vezes superestimarem o nível de sua participação religiosa.

Quanto às regularidades observadas por estudiosos de outras áreas, como os sociólogos da religião, no comportamento religioso dos indivíduos, Azzi e Ehrenberg (1975) destacam os seguintes fatos estilizados:

1. As mulheres tendem a participar mais em atividades religiosas do que os homens;

2. A frequência à igreja tende a aumentar conforme a idade das pessoas aumenta, com a exceção das pessoas mais velhas ou idosas, em decorrência de problemas de saúde;

3. A correlação entre renda e frequência à igreja seria positiva, mas relativamente fraca;

4. Pessoas de cor negra frequentariam mais a igreja do que pessoas de cor branca;

5. A frequência religiosa seria maior em áreas rurais do que em áreas urbanas.

Embora o modelo seja mais amplo, como se verá, permitindo o teste de diversas hipóteses, são os cinco fatos estilizados acima, ajustados ao modelo, que se pretende testar neste artigo.

Após essa introdução, será apresentado formalmente e discutido em seguida o modelo de participação religiosa de Azzi e Ehrenberg (1975). Na seção 3 serão apresentados os resultados empíricos do 
modelo encontrados na literatura, além dos testes econométricos do modelo com dados da Pesquisa Social Brasileira - PESB (2004). Por último, são feitas as considerações finais.

\section{O Modelo de Participação Religiosa}

Os indivíduos religiosos, segundo Azzi e Ehrenberg (1975), frequentariam igrejas por, pelo menos, três razões. A primeira estaria condicionada à crença, chamada pelos autores de "motivo salvação", que indivíduos religiosos teriam sobre o seu consumo no período pós-vida, o qual estaria, segundo essa crença, relacionado à sua frequência à igreja. A segunda razão se fundamentaria na utilidade que os indivíduos religiosos derivariam de sua participação religiosa no presente, como resultado de suas crenças inerentes ou por causa de fatores sociais. O terceiro fator seria que, numa comunidade religiosa como uma igreja, a participação em atividades eclesiásticas aumentaria a probabilidade de sucesso material. Os autores chamam esse fator de "motivo de pressão social" e teria maior peso quanto menos igrejas houvesse em uma determinada região e quanto mais recentes fossem os membros. O modelo de Azzi e Ehrenberg destaca principalmente o "motivo salvação".

Inicialmente considera-se uma família composta de dois membros: marido e mulher, onde se assume que ambos possuem uma ordenação de preferências representadas por uma função de utilidade quase-côncava.

$$
U=U\left(C_{1}, C_{2}, \ldots, C_{t}, \ldots, C_{n}, q\right)
$$

Onde $C_{t}$ representa o consumo esperado da família no tempo $t$ e $q$ representa o valor esperado do consumo no período pós-vida. Assume-se que ambos sabem antecipadamente a duração de suas vidas e que irão morrer no final do período $n$. Ambos também sabem qual o nível de salário que receberão no presente e no futuro, os quais são predeterminados no modelo.

O consumo no período $t$ é dado por uma função de produção doméstica, a qual transforma as aquisições, pela família, de um bem de mercado composto $x_{t}$, e o tempo de alocação para o consumo utilizado pelo marido $\left(h_{1 t}\right)$ e pela esposa $\left(h_{2 t}\right)$ em unidades de commodi- 
ties de consumo final $\left(C_{t}\right)$. Assume-se que essa função é inalterável intertemporalmente, continuamente diferenciável e côncava.

$$
C_{t}=C\left(x_{t}, h_{1 t}, h_{2 t}\right) \forall t
$$

A função que representa o consumo esperado do período pós-vida é considerada continuamente diferenciável e côncava quanto ao tempo gasto em atividades eclesiásticas pelo marido e pela esposa ao longo de suas vidas

$$
q=\left(r_{11}, r_{12}, \ldots, r_{1 n}, r_{21} \ldots, r_{2 n}\right)
$$

A concavidade da função de produção do consumo pós-vida é justificada pelos autores tendo em vista que se a mesma fosse estritamente convexa, isso resultaria em soluções de canto, em que os indivíduos estariam alocando todo o seu tempo em atividades religiosas. Tais pessoas seriam minoria e não iriam alterar o seu comportamento em resposta a alterações nas variáveis do modelo. A forma específica da função é determinada pelas crenças dos indivíduos que constituem a família. Aqueles que consideram o valor de $q$ como sendo nulo seriam os descrentes. ${ }^{22}$ No contexto do modelo, esses indivíduos não alocariam nenhuma parcela de seu tempo em atividades religiosas. Em modelos baseados em pressão social, o envolvimento nessas atividades seria considerado racional.

2 Cumpre destacar que existem variantes religiosas que não dão respaldo a crenças em uma vida futura, como o zen-budismo. No entanto, esse fato não é mencionado por Azzi e Ehrenberg, que tratam os indivíduos que não creem numa vida além-morte como se fossem todos descrentes. Mesmo entre adeptos de religiões que enfatizam uma vida pós-morte, existem aqueles que não acreditam nisso como um fato. Em uma das tabelas apresentadas no artigo de Azzi e Ehrenberg, sobre frequência religiosa e crença no período pós-vida, baseada em pesquisas realizadas pelo Instituto Gallup em 1973, nos EUA, enquanto entre católicos e adeptos protestantes de várias denominações a crença no período pós-vida superava $70 \%$ do total dos entrevistados, em média, entre judeus pesquisados essa crença não ultrapassava os $17 \%$. Não custa ressaltar que o judaísmo, no início, não acreditava num período pós-vida, o que só veio acontecer mais tarde, principalmente por causa da influência do Zoroastrismo persa. No Brasil, conforme levantamento de pesquisa amostral efetuada pelo Instituto Datafolha, entre 19 e 20 de março de 2007, com 5.700 indivíduos, em 236 municípios de vários estados brasileiros, a crença absoluta no período pós-vida entre os entrevistados, em termos percentuais, ficou assim distribuída, por ordem decrescente: 92\% entre os espíritas kardecistas e espiritualistas, $84 \%$ entre os adeptos do candomblé e de outras religiões afro-brasileiras, $69 \%$ entre os umbandistas, $62 \%$ entre os católicos, $60 \%$ entre os evangélicos pentecostais, $55 \%$ entre os evangélicos não pentecostais e $54 \%$ entre os adeptos de outras religiões. Essas e outras informações dessa pesquisa do Instituto Datafolha podem ser obtidas por meio de download das tabelas completas em http://datafolha.folha.uol.com.br/folha/datafolha/ tabs/religiao_03052007_tb4.pdf Ver a pergunta de número 49. (acessado em 10/01/2013). 
Chame-se de $p$ o preço de um bem de mercado em qualquer período, $\omega_{1 \mathrm{t}}$ e $\omega_{2 \mathrm{t}} \mathrm{o}$ nível de salário do marido e da esposa, respectivamente, no período $t ; i$ uma taxa de juros constante, $v$ a renda exógena intertemporal não laboral da família, $l_{1}$ e $l_{2}$ as horas de trabalho do marido e da esposa em cada período $t$, respectivamente. Considerando que a família não pretende deixar nenhum tipo de herança para seus descendentes, então a sua restrição orçamentária descontada ao longo da vida seria dada por:

$$
\sum_{t=1}^{n} \frac{p x_{t}}{(1+i)^{t-1}}=\sum_{t=1}^{n} \frac{\left(v+\omega_{1 t} l_{1 t}+\omega_{2 t} l_{2 t}\right)}{(1+i)^{t-1}}
$$

Sendo $T$ o tempo total disponível intertemporalmente, a restrição de tempo enfrentada pela família é dada por

$$
\begin{aligned}
& h_{j t}+r_{j t}+l_{j t}=T \quad \forall t=1,2, \ldots, n \quad \text { e } j=1,2 \\
& x_{t}, h_{j t}, r_{j t}, l_{j t} \geq 0 \quad \forall t \quad \text { e } j
\end{aligned}
$$

Onde $x_{t}, h_{j t}, r_{j t}$ e $l_{j t}$, representam, respectivamente, o bem de mercado composto, o tempo de alocação para o consumo, o tempo gasto em atividades religiosas e as horas de trabalho.

O problema de maximização do modelo fundamenta-se nas Equações de (1) a (6). Substituindo as funções de produção (2) e (3) na Equação (1) obtém-se uma função-objetivo composta. A restrição de tempo pode ser resolvida para $l_{1 t}$ e $l_{2 t}$ e substituída em (4) para resultar em uma função de "riqueza plena", o que permite escrever o Lagrangiano para o problema em questão

$$
\begin{aligned}
& L=U\left[C\left(x_{1}, h_{11}, h_{21}\right), C\left(x_{2}, h_{12}, h_{22}\right), \ldots C\left(x_{n}, h_{1 n}, h_{2 n}\right), q\left(r_{11}, r_{12}, \ldots r_{1 n}, r_{21}, \ldots ., r_{2 n}\right)\right]+ \\
& \lambda\left(\sum_{t=1}^{n} \frac{p x_{t}}{(1+i)^{t-1}}\right)-\sum_{t=1}^{n}\left\{\frac{\left[v+\sum_{j=1}^{2} \omega_{j t}\left(T-h_{j t}-r_{j t}\right)\right]}{(i+1)^{t-1}}\right\}
\end{aligned}
$$


Tomando como premissas de que soluções existem, as condições de primeira ordem exigem que no ótimo seja atendida a seguinte condição

$$
\frac{\frac{\partial q}{\partial r_{1 t}}}{\frac{\partial q}{\partial r_{2 t}}}=\frac{\omega_{1 t}}{\omega_{2 t}} \forall t
$$

Tomando como premissa a hipótese de que o marido e a esposa sejam ambos igualmente eficientes na produção de benefícios esperados no período pós-vida, de modo que ambos alocam a mesma quantidade de tempo em atividades religiosas, os seus respectivos "produtos marginais" na produção de benefícios esperados no período pós-vida serão igualados nesse período.

Dessa forma, a Equação (8) nos diz que se os salários do marido e da mulher forem os mesmos no mercado de trabalho, ambos irão alocar a mesma quantidade de tempo em atividades religiosas. Por outro lado, se o salário do marido for maior em relação ao da esposa, esta irá alocar uma quantidade maior de tempo em atividades religiosas. Assim, a diferença salarial entre gêneros, em favor dos homens, seria uma possível explicação do porquê de as mulheres alocarem mais tempo em atividades religiosas relativamente aos maridos.

De maneira análoga, a diferença salarial entre etnias, em favor de pessoas de cor branca, é uma possível explicação para o fato estilizado onde pessoas de cor negra alocam uma quantidade maior de tempo em atividades religiosas.

Pressupondo que marido e esposa recebam salários constantes ao longo de suas vidas, as condições de primeira ordem para um ótimo serão dadas por

$$
\frac{\frac{\partial q}{\partial r_{j t}}}{\frac{\partial q}{\partial r_{j t-1}}}=(1+i)^{-1} \quad \forall t \quad \text { e } j=1 \quad \text { ou } 2
$$


A condição acima significa que os membros da família devem alocar tempo para atividades religiosas apenas quando estiverem em idade madura. Isso porque, se para um indivíduo o produto marginal da alocação de uma hora adicional para atividades religiosas é o mesmo para os períodos $t-1$ e $t$, quando o indivíduo aloca o mesmo número de horas para os dois períodos, o tempo dedicado às atividades religiosas, para cada período, deveria aumentar conforme aumenta a idade.

Os modelos tradicionais de acumulação de capital humano mostram que o indivíduo maximiza seu retorno de investimento quando este é feito nos períodos iniciais de seu ciclo de vida, de modo que se possa recuperar o investimento em um grande número de anos posteriormente. Por outro lado, o modelo de investimento de capital religioso de Azzi e Ehrenberg (1975), indica que é ótimo investir em atividades religiosas apenas em estágios posteriores do ciclo de vida, já que esse tipo de investimento somente irá gerar retorno no período pós-vida. Desse modo, os fatores que geram uma função de investimento em capital humano monotonicamente decrescente com a idade dão suporte à geração de uma função de investimento em capital religioso monotonicamente crescente com a idade.

Se em dois períodos subsequentes $t-1$ e $t$ as taxas salariais dos membros da família sofrerem variação, então a Equação (9) passa a ser

$$
\frac{\frac{\partial q}{\partial r_{j t}}}{\frac{\partial q}{\partial r_{j t-1}}}=\frac{\omega_{j t}}{\omega_{j t-1}}(1+i)^{-1} \quad \text { e } j=1 \text { ou } 2
$$

Assim, quanto mais rápido aumentar a taxa salarial menor será a velocidade com que irá aumentar a alocação de tempo para atividades religiosas. Sabendo que as diferenças de variação na taxa de salário relativamente à idade são mais acentuadas para os homens do que para as mulheres, então, por outro lado, dá-se exatamente o oposto na alocação de tempo para as atividades religiosas, onde a variação nesse quesito relativamente à idade é maior no caso das mulheres. Isto é, conforme avança a idade, as mulheres irão aumentar o tempo alocado em atividades religiosas mais rapidamente que os homens, já que o custo marginal de investimento em capital religioso cresce 
numa velocidade menor para o sexo feminino relativamente ao sexo masculino.

Se a taxa de incremento salarial entre dois períodos é significativa, isso pode fazer com que o efeito de desconto seja superado, fazendo com que a alocação de tempo em atividades religiosas venha a declinar entre dois anos. A curva de ganhos versus idade tende a ser côncava, em que a taxa de incremento salarial diminui com o avanço da idade. Já a curva de comportamento religioso tende a ter a forma de $U$, em que a alocação de tempo para atividades religiosas inicialmente diminui com a idade para depois aumentar.

As condições de otimização do modelo também permitem que se calcule o impacto sobre as atividades religiosas relativamente ao auferimento de renda não laboral exógena ou de uma mudança intertemporal na taxa de salários. Considerando que o consumo pós-vida seja um bem normal, um aumento exógeno no nível de renda não laboral teria como resultado o aumento na alocação de tempo para atividades religiosas, ou seja:

$$
\frac{\partial r_{j}}{\partial \omega}>0 \quad \forall j=1 \text { ou } 2
$$

O efeito de uma alteração salarial sobre o comportamento religioso de um indivíduo pode ser decomposto em dois: efeito substituição e efeito renda, conforme mostrado a seguir

$$
\frac{\partial r_{j}}{\partial \omega_{j}}=\left(\frac{\partial r_{j}}{\partial \omega_{j}}\right)^{*}+l_{j} \frac{\partial r_{j}}{\partial v_{j}} \forall j=1 \text { ou } 2
$$

Adotando premissas fracas, pode ser demonstrado que o efeito renda tende a ser positivo e o efeito substituição, negativo.

Todas as implicações, conforme observam Azzi e Ehrenberg (1975), resultantes do seu modelo, o qual se considera que a morte é prevista antecipadamente e marido e mulher sabem a extensão de suas vidas, também podem ser deduzidas de um modelo em que a morte é incerta. Isso é verdadeiro, desde que se tomem como premissas as hipóteses de que marido e mulher morrem ao mesmo tempo, que 
a probabilidade de morte de modo prematuro é pequena e que o consumo esperado da etapa pós-vida inicia no período $n+1$, independentemente da época em que a morte venha a acontecer.

No entanto, quando a probabilidade de morte é suficientemente grande, o nível de participação religiosa tende a aumentar, uma vez que o indivíduo pode rapidamente morrer sem realizar investimentos em capital religioso que lhe permitam um retorno em forma de consumo pós-morte.

\section{Testes Empíricos do Modelo na Literatura}

Os testes econométricos visando testar as implicações do modelo foram baseados em dois tipos de dados: dados estaduais de número de membros de igrejas nos EUA para os anos de 1926, 1936 e 1952; e frequência à igreja ao longo do ano de 1973 para aproximadamente 1.500 adultos. Ambos os dados foram tomados como proxies para a variável dependente do modelo a ser testado.

Azzi e Ehrenberg (1975), enfatizam que os dados são precários quanto à sua qualidade, por causa de erros de registro e de cobertura incompleta, como falta de dados ou de subestimação de número de membros de igrejas "negras". Quanto à definição do que constitui um membro de uma igreja, o conceito varia entre religiões e no tempo. A Igreja Católica, por exemplo, define membro de suas fileiras todo aquele que foi batizado, incluindo crianças recém-nascidas. Já as denominações protestantes consideram como membro somente aqueles que têm condições de fazer profissão de fé, geralmente pessoas já adultas. Entre os judeus, após completarem doze anos e passarem pela cerimônia de Bar-Mitzvá, os adolescentes do sexo masculino passam a ser considerados adultos, assumindo todas as funções religiosas que podem ser exercidas em uma sinagoga, como a leitura e comentário da Torá e a guarda dos livros. Algo idêntico acontece com adolescentes judias do sexo feminino ao completarem treze anos, que passam por uma cerimônia semelhante e são integradas oficialmente à comunidade judaica como adultos plenos. No entanto, em uma das pesquisas utilizadas por Azzi e Ehrenberg, apenas os judeus pais de família foram considerados membros. 
Os autores utilizaram regressões cross-section para cada ano com o objetivo de explicar as variações interestaduais no número de membros. As variáveis explicativas que são relacionadas ao modelo estão baseadas em dados de estruturas de idade e gênero de populações estaduais, salários médios recebidos por homens e mulheres, e indicadores de renda não laboral e de riqueza. Foram incluídas também como variáveis explicativas, para controle dos erros de medida, percentagens da população estadual classificada como judia e católica, percentagem de população não branca e densidade demográfica da população estadual.

$\mathrm{Na}$ avaliação dos resultados para a pesquisa de 1952, constatouse que quanto maior a percentagem da população feminina numa amostra, maior o número de adeptos religiosos/frequência à igreja (variável dependente do modelo). A variável riqueza, medida tanto pela mediana da renda familiar ou da mediana da renda do chefe de família, e a variável idade também tiveram um efeito positivo sobre o percentual de membros/frequência à igreja. Já a variável referente a salários de homens e mulheres esteve correlacionada negativamente com a variável dependente. Todas as variáveis apresentaram significância e apresentaram o sinal conforme previsto pelo modelo.

Para os anos de 1926 e 1936 os testes constataram também que houve um efeito positivo da variável riqueza sobre a variável dependente e um efeito negativo referente a salários. Incrementos na idade estão correlacionados negativamente com a variável dependente. Por outro lado, amostras com maior percentual de população idosa tiveram influência positiva sobre o número de membros/frequência religiosa. Isso está de acordo com o previsto pelo modelo, que prevê um formato em $U$ para a curva que relaciona idade e frequência religiosa. Outro resultado interessante para aqueles anos foi o de que incrementos na população masculina tiveram influência negativa sobre a variável dependente. Para o ano de 1926, incrementos na força de trabalho masculina tiveram efeito negativo sobre a variável explicada. Por outro lado, o mesmo não se verificou no caso de aumento de participação de mulheres no mercado de trabalho.

Em termos gerais, os dados da pesquisa de 1952 dão suporte consistente às implicações do modelo. Já as pesquisas de 1926 e de 1936, embora os seus dados confirmem as previsões do modelo para a influência da riqueza e da renda sobre o número de membros/fre- 
quência religiosa, não dão o mesmo respaldo para os efeitos previstos pelo modelo no caso das variáveis gênero e idade.

Já o levantamento de 1973 para uma amostra de 1.504 adultos norte-americanos inclui sua frequência anual à igreja ou sinagoga. Os entrevistados foram questionados em relação à sua crença sobre uma vida pós-morte, em que $76 \%$ dos protestantes, $70 \%$ dos católicos e $17 \%$ dos judeus responderam de modo afirmativo à pergunta. A pesquisa tem algumas limitações, como o fato de incluir apenas os dados de homens relativamente à frequência à igreja e de não incluir dados relativos a salários. Com isso, os autores tiveram que usar variáveis proxies para tentar sanar essa lacuna. A amostra foi dividida em cinco grupos religiosos: protestantes, católicos, metodistas, luteranos e batistas. Constatou-se que a frequência religiosa varia positivamente conforme aumenta a idade para todos os grupos; que as mulheres frequentam mais a igreja do que os homens; ${ }^{3}$ que não brancos são mais assíduos ao serviço religioso do que os brancos. A crença no período pós-vida e crenças idênticas dos cônjuges incrementam de forma significativa o nível de participação religiosa, que também é influenciada positivamente pela renda familiar total até um determinado nível, quando então passa a decrescer (no caso dos protestantes, metodistas e luteranos).

Os resultados da regressão indicam que o nível de participação religiosa é maior pelo menos em três casos em que foram utilizadas variáveis de controle: minorias raciais, já que a discriminação pode restringir suas alternativas de consumo; idênticas crenças religiosas do marido e da mulher; e famílias com crianças em idade escolar. Em contrapartida, a presença de crianças em idade pré-escolar e de pessoas com problemas de saúde tende a reduzir a participação religiosa.

Long e Settle (1977) realizaram um estudo, baseado em uma pesquisa com chefes de família de Wisconsin, em que empregaram variáveis adicionais para testar o modelo de Azzi e Ehrenberg (1975), tais como renda não salarial, mobilidade familiar e o nível de crença dos pais dos entrevistados, considerando que, ceteris paribus, esta última influencia positivamente o comparecimento dos filhos à igreja. Estes pertenciam a três filiações religiosas: protestantes, católicos e

3 Stolzemberg, Blair-Loy e Late (1995) citam outros estudos que indicam ser a frequência religiosa das mulheres maior que a dos homens. Entre estes estudos estão o de Vaus e MClister (1987), Hout e Greeley (1987), Cornwall (1989), Ellison et alli (1989) e Ploch e Hastings (1993). 
luteranos. Long e Settle apontam que o estudo apresenta a vantagem de restringir a amostra de modo a incluir apenas famílias que: a) tenham informação de ambos os cônjuges e b) revelem a informação das fontes e nível de renda familiar. Estas informações não foram incluídas no teste realizado por Azzi e Ehrenberg (1975) ou, no máximo, o foram por meio de proxies.

Os resultados da regressão com os três grupos religiosos não confirmaram, em sua maioria, as predições do modelo de Azzi e Ehrenberg (1975), Suas estimativas não encontraram ligação entre comparecimento à igreja e idade, renda não salarial, riqueza, ou o número de crianças em idade pré-escolar. No caso da idade, os autores argumentam que, possivelmente, a não incorporação da variável referente ao estado de saúde do entrevistado possa ter viesado o resultado, já que um estado de saúde precário tende a diminuir o comparecimento à igreja, além de considerar que esta variável está positivamente correlacionada à idade. Também foi apontada uma fraca relação entre renda do cônjuge feminino e frequência à igreja. As variáveis que apresentaram impacto positivo sobre a frequência à igreja foram crença no período pós-vida, número de crianças em idade escolar e idênticas crenças religiosas do marido e da mulher, o que esteve de acordo com o modelo de Azzi e Ehrenberg (1975) Long e Settle (1977) incorporaram variáveis de controle, como mobilidade da família, profissão e nível de crença dos pais do entrevistado, as quais não demonstraram ter qualquer impacto significativo sobre o comparecimento à igreja.

Ehrenberg (1977) apresenta um novo teste para o modelo com novos dados, confirmando as previsões do modelo desenvolvido com Azzi, além de refutar as objeções de Long e Settle (1977). Em primeiro lugar, Ehrenberg aponta que aqueles dois autores empregaram amostras relativamente pequenas, o que reduziria a probabilidade de se obter coeficientes estatisticamente significativos e incrementar o $\mathrm{R}^{2}$. Em segundo lugar, aponta que a falta de correlação entre idade e comparecimento à igreja no estudo de Long e Settle (1977) poderia ser explicado como decorrência da não inclusão do estado de saúde dos entrevistados, o que teria gerado um viés nos resultados. Terceiro, a restrição do estudo a pessoas do sexo masculino, no caso de Long e Settle (1977), impediu que se pudessem testar as implicações referentes ao diferencial de sexo na participação religiosa, o que, segundo Ehrenberg (1977), é fundamental para a confirmação das predições do 
modelo. Em quarto lugar, as variáveis referentes à salário, renda não salarial e riqueza apresentam problemas de medidas de erro, o que certamente teria influenciado os resultados.

Por outro lado, Ulbrich e Wallace $(1983,1984)$ não encontraram nenhuma evidência de que expectativas do período pós-vida tenham quaisquer impactos sobre a relação entre frequência religiosa e idade, nem que o fato de as mulheres terem salários mais baixos, relativamente aos homens, tenha influência sobre o maior nível de frequência religiosa de membros de igrejas do sexo feminino.

Já Sullivan's (1985) empregou equações simultâneas para testar a relação entre contribuições e comparecimento à igreja, encontrando fracas evidências que confirmassem o modelo.

Utilizando dados relativos a trabalhadores judeus do sexo masculino residentes em Israel, Neuman (1986) constatou, para a sua amostra, que o tempo alocado para a prática religiosa estava correlacionado negativamente à taxa de salário, que existia uma relação em formato de " $U$ " entre a idade e a prática religiosa, onde o ponto mínimo médio era de 43 anos, isto é, até esta idade, o tempo alocado para a religiosidade diminuía, passando a aumentar a partir deste ponto. Um resultado interessante obtido por Neuman (1986), foi constatar que, com o aumento de escolaridade, o ponto mínimo da relação idade versus tempo alocado para a religião era deslocado para a direita. Assim, para homens com escolaridade de 0 a 8 anos, o ponto mínimo era de 36 anos, enquanto para escolaridade entre 9 e 12 anos a idade passava a ser de 40 anos; já para um nível de escolaridade superior a 13 anos o ponto mínimo passava a ser de 6 anos.

Harley e Firebaugh (1993), baseados em dados do General Social Survey (GSS) entre 1973 e 1991, concluíram que a crença no período pós-vida entre os norte-americanos mudou muito pouco nesse período. Também observaram que essa crença não aumenta de modo significativo com o passar do tempo, e que não está diminuindo como seria esperado em função dos efeitos cohorts de nascimentos. Já Heineck (2001), usando dados do German Socio-Economic Panel (GSOEP) e aplicando um modelo probit com equações para frequência religiosa e para intensidade da fé relativamente a homens e mulheres, de modo separado, encontrou evidências de que a idade é um forte preditor para o comparecimento à igreja na Alemanha. 
Empregando uma amostra com dados relativos a cristãos, mulçumanos, judeus e hindus de ambos os sexos, residentes no Reino Unido, Loewenthal, MacLeod e Cinnirela (2002) encontraram evidências de que apenas entre os cristãos pode ser detectado um nível de prática religiosa superior entre as mulheres, relativamente aos homens, enquanto que para as demais religiões pesquisadas os homens se mostraram mais religiosos relativamente às mulheres. Os autores concluíram que o fato estilizado de que as mulheres são mais religiosas do que os homens depende do contexto cultural-religioso analisado e do método utilizado.

Barros (2003), aplicando um modelo modificado de Sullivan (1985) que utiliza a função de produção doméstica de Becker (1965) procurou investigar o perfil da prática religiosa em Portugal. O autor utilizou dados da pesquisa denominada Atitudes e Práticas Religiosas dos Portugueses e empregou um modelo logit binomial. Os resultados apontaram que a frequência à igreja, tomada como variável endógena, depende da crença em Deus, e que as mulheres e as pessoas mais velhas vão mais à igreja. Não se constatou qualquer influência da renda, da classe social e da situação profissional sobre a frequência à igreja.

Empregando um modelo de regressão logit ordenado, Brañas-Garza e Neuman (2004), a partir de dados obtidos de uma amostra de católicos espanhóis, constataram que a prática religiosa era mais intensa entre as mulheres e entre pessoas mais velhas. A prática religiosa dos homens estava correlacionada positivamente ao número de filhos pequenos e ao fato de serem casados. A crença no período pós-vida também esteve associada positivamente à prática religiosa de ambos os sexos.

Com dados do International Social Survey Programme (ISSP) de 1998, para a frequência religiosa na Espanha entre 1930-1992, Brañas-Garza (2004) constatou que a taxa de declínio para essa variável foi de $2 \%$ ao ano no período analisado.

Em outro estudo, Brañas-Garza e Neuman (2008), usando dados do International Social Survey Program para a Espanha, empregaram um índice de prática religiosa e outro de crenças religiosas como variáveis dependentes e informações sociodemográficas como variáveis independentes. Esses autores observaram em seus resultados que a prática religiosa e a crença dos indivíduos estão correlacionadas, e 
que mulheres, pessoas mais velhas e pessoas casadas são mais inclinadas à prática religiosa. $\mathrm{O}$ efeito da educação sobre a prática religiosa apresentou correlação negativa.

Rossi e Rossi (2008) empregaram dados de países latino-americanos e europeus para investigar a relação entre frequência religiosa e algumas variáveis socioeconômicas. Seus resultados apontam para evidências de que a prática religiosa é mais intensa entre mulheres e está positivamente associada à idade e à renda individual, embora os países de renda per capita mais elevada tenham apresentado menor nível de religiosidade. Além disso, concluíram que os efeitos da educação sobre a prática religiosa são ambíguos.

\section{Testes Econométricos do Modelo de Azzi-Ehrenberg com Dados da Pesquisa Social Brasileira-PESB (2004)}

Uma das dificuldades de realizar testes de modelos de Economia da Religião, como o de Azzi e Ehrenberg, com dados de países em desenvolvimento, entre eles o Brasil, diferentemente de países desenvolvidos como os EUA, é a escassez de informações sobre frequência religiosa (semanal, mensal, anual, etc), filiação religiosa e níveis de crenças, oriundas de pesquisas científicas, que permitam fazer esses testes. Esse é o principal motivo para existirem tão poucos estudos no Brasil, nessa área. Entre esses, podem ser citados Anuatti-Neto e Narita (2004) e Oliveira et alii (2011).

Dentre essas raras bases de dados, e com caráter pioneiro, por exemplo, está a Pesquisa Nacional por Amostra de Domicílios de 1988 (PNAD 88) realizada pelo IBGE em 1988, em cujo Suplemento de Participação Político-Social, no item 2.9, parte 9, foram inseridas algumas perguntas referentes à religião e, principalmente, sobre frequência religiosa de 197.509 entrevistados de todo o país.

Outra desses escassos bancos de dados, contendo informações sobre frequência religião, é a Pesquisa Social Brasileira (PESB) ${ }^{4}$ de 2004 (edição mais recente no momento deste estudo). Esta pesquisa é a que será utilizada neste trabalho, por ser mais atualizada.

4 Para outras informações sobre a PESB consultar http://www.uff.br/datauff/PESB.htm (acessado em 22/02/2013). 
Ela foi realizada pela FGV-Opinião (com 1.524 entrevistados de várias cidades do país), que é um instituto de pesquisa ligado ao Centro de Pesquisa e Documentação da História Contemporânea do Brasil, da Fundação Getúlio Vargas (FGV), e patrocinada pela Fundação Ford. Tem similaridades com o GSS (General Social Survey), realizado anualmente nos EUA e sob responsabilidade do National Opinion Research Center (NORC), da Universidade de Chicago e do British Social Atitudes, realizado no Reino Unido. No entanto, a abrangência da PESB é mais restrita, já que o seu conjunto de variáveis é bem inferior ao do GSS, por exemplo. O GSS mais recente, o de 2006, possui mais de 5.000 variáveis. Já a PESB possui pouco mais de 900 variáveis.

A PESB é uma pesquisa probabilística, realizada com entrevistados (eixo de análise) em domicílios sorteados em todo o país, no meio urbano e rural, tendo, portanto, âmbito nacional. A PESB 2004 incluiu questões sobre religião, com uma pergunta sobre a frequência religiosa dos entrevistados, uma sobre filiação religiosa e outras duas sobre níveis de crença religiosa.

Pelo nosso conhecimento este é o primeiro trabalho, no Brasil, a fazer uso dos dados da PESB 2004 para testar um modelo de Economia de Religião. A variável dependente utilizada foi frequência à missa ou a culto religioso. Sexo, idade, cor (etnia), lugar do domicílio (urbano/rural) e renda familiar foram utilizados como variáveis explicativas. Tanto para simplificação de cálculos, quanto para facilidade de interpretação dos resultados, os oito níveis de frequência religiosa explicitados no questionário da PESB foram resumidos a quatro níveis de frequência: alta, média, baixa e nunca. No questionário, as pessoas podiam escolher entre oito categorias de frequência religiosa. A recategorização foi realizada da seguinte forma: ${ }^{5}$

5 A simplificação da análise e da interpretação dos resultados do modelo foi importante para esta recategorização. No entanto, o motivo principal da adoção deste procedimento foi outro. A maneira como foram formuladas as perguntas da PESB, em nossa ótica, pode não ter sido a mais apropriada para a efetividade e a clareza das respostas obtidas. Isso poderia ter implicações em termos de perda de eficiência e de robustez, a partir desse viés, no tratamento estatístico dos dados em nosso estudo. Acreditamos que muitas respostas podem ter apresentado, em decorrência da forma como as perguntas foram formuladas, um significado ambíguo. É o caso, por exemplo, de um entrevistado ter respondido "Uma vez por mês", ao ser indagado sobre sua frequência religiosa. Tal resposta poderia significar, também, que esse indivíduo tem uma frequência de mais de uma vez por ano e, portanto, poderia ter respondido com esta alternativa. Com isto, estaríamos "corrigindo" esta ambiguidade com a agregação entre frequências religiosas, ao empregarmos categorias mais amplas, como Alta, Média e Baixa. Portanto, reduzimos a variabilidade, mas tornamos mais robustas tanto a qualidade de interpretação, como a confiabilidade das categorias. 
Alta: Mais de uma vez por semana, Uma vez por semana, e Duas ou três vezes por mês.

Média: Uma vez por mês, e Mais de uma vez por ano.

Baixa: Uma vez por ano, e Raramente.

Nunca: Nunca.

A seguir temos uma tabela que mostra a frequência relativa da variável dependente.

Tabela 1 - Nível de frequência

\begin{tabular}{c|c}
\hline Frequência de Alternativas & $\%$ \\
\hline Alta & 49,83 \\
\hline Média & 25,21 \\
\hline Baixa & 19,1 \\
\hline Nunca & 5,87 \\
\hline
\end{tabular}

\subsection{Análise Preliminar: Associação entre as Covariáveis e a Variável Resposta}

Para fazer a regressão logística ordenada analisa-se a relação de cada covariável com a variável resposta como sondagem preliminar, a fim de verificar associações univariadas, levantar hipóteses e descrever estas relações sem influência de outras variáveis no modelo completo.

\subsubsection{Sexo e Frequência Religiosa}

Adiante temos uma tabela que indica a distribuição da frequência relativa masculina e feminina nos quatro níveis de frequência religiosa, além do resultado do teste qui-quadrado.

Tabela 2 - Frequência relativa por gênero

\begin{tabular}{c|c|c}
\hline Freq. Rel. & Masculino & Feminino \\
\hline Alta & 238 & 522 \\
\hline Média & 194 & 180 \\
\hline Baixa & 131 & 153 \\
\hline Nunca & 61 & 32 \\
\hline
\end{tabular}

$\chi^{2}=73.8$, Valor-p $=\mathbf{0 , 0 0 1}$ 
Foi realizado o teste qui-quadrado para verificar a associação entre gênero e a frequência religiosa. Notou-se que o valor-p resultou num valor altamente significativo (Valor-p $=6,365 \times 10^{-16}<0,001 \mathrm{com}$ um $\alpha=5 \%$ ). Concluímos que, de uma perspectiva univariada, existe associação significativa entre o gênero das pessoas e a sua frequência religiosa. Ou seja, as variáveis não são independentes.

Para verificar onde estão estas associações, podemos ver os resíduos padronizados e compararmos com os valores de uma Normal Padrão. A tabela contendo os resíduos da frequência relativa por gênero segue adiante:

Tabela 3 - Resíduos padronizados

\begin{tabular}{ccc}
\hline Freq. Rel. & Feminino & Masculino \\
\hline Alta & 3,59 & $-4,28$ \\
\hline Média & $-2,66$ & 3,18 \\
\hline Baixa & $-1,06$ & 1,26 \\
\hline Nunca & $-3,05$ & 3,64 \\
\hline
\end{tabular}

Trabalhando com 95\% de confiança, valores acima de 1,96 são significativamente acima do esperado (sob independência) e valores abaixo de -1,96 são significativamente abaixo do esperado. Pode ser observado que existe uma associação positiva e significativa, ao nível de $5 \%$, entre frequência relativa alta e o sexo feminino, o que corrobora a hipótese do modelo de Azzi e Ehrenberg (1975). Nunca ter frequência religiosa é um evento que está associado positivamente ao fato do entrevistado ser do sexo masculino.

\subsubsection{Idade e Frequência Religiosa}

Foi realizada uma análise de variância univariada One-Way que resultou em um valor-p significativo (valor- $\mathrm{p}=5,346 \times 10^{-6}$ ), ilustrando uma relação significativa (nesta perspectiva sem covariáveis) entre idades e frequência religiosa.

Algumas estatísticas descritivas são apresentadas a seguir: 
Tabela 4 - Estatísticas descritivas de idade dos entrevistados

\begin{tabular}{ccccccc}
\hline Freq. Rel. & Mínimo & 10 Quartil $^{\text {Mediana }}$ & Média & $3^{\circ}$ Quartil & Máximo \\
\hline Alta & 18 & 28 & 41 & 43,4 & 57 & 95 \\
Média & 18 & 30 & 39 & 42,21 & 53 & 87 \\
Baixa & 18 & 26 & 35 & 38,18 & 47 & 97 \\
Nunca & 18 & 24 & 34 & 39,12 & 50 & 98 \\
\hline
\end{tabular}

\subsubsection{Etnia e Frequência Religiosa}

A seguir temos uma tabela que indica a distribuição da frequência relativa das etnias representadas na amostra (branca, amarela, indígena, parda e preta) segundo os quatro níveis de frequência religiosa, além do resultado do teste qui-quadrado.

Tabela 5 - Frequência relativa segundo a etnia

\begin{tabular}{cccccc}
\hline Freq. Rel. & Branca & Amarela & Indígena & Parda & Preta \\
\hline Alta & 337 & 14 & 26 & 270 & 80 \\
\hline Média & 149 & 16 & 17 & 141 & 42 \\
\hline Baixa & 124 & 15 & 7 & 96 & 31 \\
\hline Nunca & 42 & 1 & 3 & 31 & 11 \\
\hline
\end{tabular}

$\chi^{2}=15.6, \mathrm{df}=12$, Valor-p $=0.209$

Acima, encontra-se o teste de associação da variável cor (etnia) e frequência religiosa que gerou um valor- $\mathrm{p}=0,209$ não significativo. Isto é, a princípio, estas variáveis possuem um comportamento independente. A frequência religiosa não está associada com a cor das pessoas.

\subsubsection{Localização e Frequência Religiosa}

Aqui serão apresentados os resultados dos testes sobre a relação entre a localização dos moradores pesquisados na amostra e as suas frequências religiosas. Adiante é apresentada uma tabela que indica a distribuição da frequência relativa dos entrevistados de acordo com a localização de suas residências (urbana ou rural), segundo os quatro níveis de frequência religiosa, além do resultado do teste qui-quadrado. 
Tabela 6 - Frequência relativa de localização

\begin{tabular}{ccc}
\hline Freq. Rel. & Zona urbana & Zona rural \\
\hline Alta & 603 & 120 \\
\hline Média & 291 & 65 \\
\hline Baixa & 217 & 55 \\
\hline Nunca & 86 & 6 \\
\hline
\end{tabular}

$\chi^{2}$ 9.6, Valor-p $=0.022$

Por meio desse teste, conclui-se que existe uma associação significativa entre a variável de localização da moradia e a frequência religiosa (valor-p $=0,022<5 \%$ ). Os resíduos padronizados seguem adiante:

Tabela 7 - Resíduos var. localização

\begin{tabular}{ccc}
\hline Freq. Rel. & Zona urbana & Zona rural \\
\hline Alta & 0,13 & $-0,29$ \\
\hline Média & $-0,25$ & 0,55 \\
\hline Baixa & $-0,57$ & 1,26 \\
\hline Nunca & 1,10 & $-2,44$ \\
\hline
\end{tabular}

Considerando o intervalo de $95 \%$ de confiança, valores acima de 1,96 são significativamente acima do esperado (sob independência), e valores abaixo de -1,96 são significativamente abaixo do esperado. $O$ único valor observado significativo foi de 2,45 negativos para pessoas com frequência igual a "Nunca" e residentes de Zona Rural. Apontando que pessoas residentes deste meio têm uma frequência de religião igual a "Nunca" abaixo do esperado sob independência.

\subsubsection{Renda Familiar e Frequência Religiosa}

Uma análise de variância unifatorial foi realizada resultando em um valor-p não significativo (valor-p $=0,24>5 \%$ ), ilustrando uma relação não significativa entre idades e frequência religiosa. Isto é, variando a média das rendas familiares, a frequência religiosa não varia. No entanto, para fins descritivos, algumas estatísticas descritivas são apresentadas a seguir: 
Tabela 8 - Estatísticas descritivas de renda dos entrevistados

\begin{tabular}{ccccccc}
\hline Freq. Rel. & Mínimo & $1^{\circ}$ Quartil & Mediana & Média & $3^{\circ}$ Quartil & Máximo \\
\hline Alta & 30 & 350 & 690 & 1114 & 1325 & 15000 \\
Média & 20 & 360 & 707,5 & 1161 & 1400 & 11000 \\
Baixa & 50 & 400 & 700 & 1232 & 1500 & 12000 \\
Nunca & 50 & 351,5 & 600 & 1443 & 1750 & 14000 \\
\hline
\end{tabular}

\subsubsection{Renda Familiar e Etnia}

Foi realizado um teste para verificar a existência de diferença de renda familiar entre pessoas negras e brancas, conforme comentado na seção 2. A diferença absoluta entre as médias observada entre a renda familiar foi de aproximadamente 830 reais, em favor dos brancos, sendo investigada a significância dessa diferença. Para tal, foi realizado um teste-t para diferença entre médias e foi verificado diferença significativa (valor-p $<0,0001<5 \%$ ). Com isto, foi confirmada a hipótese de que negros ganham, em média, menos do que os brancos, de acordo com os dados oriundos da pesquisa realizada.

\subsection{Modelo de Resposta Categórica Ordinal}

O modelo de resposta categórica ordinal, também chamado de Modelo de Riscos Proporcionais, é uma classe dos modelos lineares generalizados usada para modelar a dependência de uma variável dependente ordenada em covariáveis discretas ou contínuas. ${ }^{6}$ Seja Y a variável dependente com os possíveis eventos $1,2, \ldots, k$, com $\mathrm{k} \geq$ 2 (ou seja, $k$ é a quantidade de categorias de Y), e seja a probabilidade cumulativa de Y até a classe $j$ quando $x$ é fixa. O modelo mais geral de regressão linear logística para a $j$-ésima probabilidade de $\mathrm{Y}$ cumulativa,

$$
\operatorname{logit}\left(\gamma_{j}\right)=\alpha_{j}-\beta_{j}^{T} x
$$

é um modelo em que ambos o intercepto $\alpha$ e o vetor de coeficientes $\beta$ dependem da categoria $j$. O modelo de resposta categórica ordinal é um modelo logístico linear no qual o intercepto depende do j, mas as inclinações são todas iguais.

6 http://www.stat.uchicago.edu/ pmcc/reports/prop_odds.pdf 
Desta forma, chegamos ao modelo

$$
\operatorname{logit}\left(\gamma_{j}\right)=\alpha_{j}-\beta^{T} x
$$

O modelo pressupõe riscos proporcionais, isto é, a relação entre quaisquer dois pares de categorias são estatisticamente iguais. Isto significa que os coeficientes que descrevem a relação entre, por exemplo, a menor versus todas as demais categorias são os mesmos dos que descrevem a relação entre a próxima categoria e todas as demais acima. O modelo não pode ser consistentemente estimado utilizando mínimos quadrados ordinários, porque é estimado utilizando máxima verossimilhança.

Exemplos de variáveis categóricas ordinais incluem pesquisas de opinião (com perguntas, por exemplo, variando "fortemente concordo" até "fortemente discordo"), níveis de gastos públicos de algum governo específico (por exemplo, alto, médio ou baixo), nível de cobertura de um plano de seguro (por exemplo, nenhum, parcial ou total), status de empregados (por exemplo, não empregado, empregado parcialmente ou empregado), qualquer tipo de categorização de uma variável quantitativa, etc. Neste trabalho, estamos trabalhando com a variável frequência religiosa com os seguintes níveis:

Tabela 9 - Categorias da variável resposta

\begin{tabular}{cc}
\hline Categoria & Resposta de Pesquisa Fornecida \\
\hline Alta & Duas ou três vezes por semana, mais de uma vez por semana e uma vez por semana \\
Média & Mais de uma vez por ano e uma vez por mês \\
Baixa & Uma vez por ano e raramente \\
Nunca & Nunca \\
\hline
\end{tabular}

Suponha que o processo a ser caracterizado e estimado é

$$
y^{*}=x^{T} \beta+\epsilon
$$

onde y* é a exata, não-observável, resposta da variável Y. Neste caso, $\mathrm{y}^{*}$ representaria o verdadeiro nível de freqüência religiosa de cada indivíduo. ${ }^{7} X$ é vetor de variáveis independentes e $\beta$ é o vetor de

7 http://en.wikipedia.org/wiki/Ordered_logit

Est. Econ., São Paulo, vol. 43, n.2, p. 335-362, abr.-jun. 2013

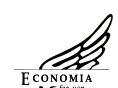


coeficientes a serem estimados. Sendo assim, como não observamos a variável $\mathrm{y}^{*}$, nós, ao invés disto, podemos apenas observar as categorias da resposta:

$$
y=\left\{\begin{array}{cc}
0, & \text { se } y^{*} \leq \mu_{1} \\
1, & \text { se } \mu_{1}<y^{*} \leq \mu_{2} \\
2, & \text { se } \mu_{2}<y^{*} \leq \mu_{3} \\
& \vdots \\
N, & \text { se } \mu_{N}<y^{*}
\end{array}\right.
$$

A técnica do modelo de regressão logística ordenada faz uso das observações de y, como uma forma da observação censurada de $\mathrm{y}^{*}$, para estimar os parâmetros $\beta$.

\section{Estimativas e Metodologia}

As estimativas foram calculadas utilizando o pacote ordinal no software R versão 2.14.0. Para as variáveis categóricas explicativas, escolhemos o gênero feminino para sexo, a cor branca para etnia e a zona urbana para a localização. O modelo estimado utilizando os dados das PESB resultante é obtido abaixo:

Tabela 10 - Resultados das estimativas

\begin{tabular}{lccccc}
\hline \multicolumn{1}{c}{ Variáveis } & \multicolumn{2}{c}{ Coeficientes } & & & \\
\hline Sexo (Masculino) & Estimativa & Erro Padrão & Valor z & \multicolumn{2}{c}{ Valor-p } \\
Idade & $-0,8791$ & 0,1115 & $-7,8830$ & 0,0000 & $* * *$ \\
Etnia (Amarela) & 0,0159 & 0,0036 & 4,3840 & 0,0000 & $* * *$ \\
Etnia (Indígena) & $-0,4486$ & 0,3015 & $-1,4880$ & 0,1368 & \\
Etnia (Parda) & $-0,1758$ & 0,3198 & $-0,5500$ & 0,5826 & \\
Etnia (Negra) & $-0,0342$ & 0,1238 & $-0,2760$ & 0,7824 & \\
Localização (Rural) & $-0,0211$ & 0,1870 & $-0,1130$ & 0,9101 & \\
Renda Familiar & 0,0066 & 0,1463 & 0,0450 & 0,9638 & \\
\hline
\end{tabular}

* $\quad$ significância a 10\%

** significância a 5\%

*** significância a $1 \%$ 
Note que temos uma estimativa para cada covariável, pois podemos interpretar seus valores como sendo constantes em cada "troca" de categoria da variável dependente. Isto é, o "risco" de passar de uma categoria Baixa $\rightarrow$ Média é o mesmo do que para Média $\rightarrow$ Alta, por exemplo. Além disto, podemos interpretar cada estimativa como a relação direta no sentido do crescimento da variável dependente, ou seja, no aumento da frequência religiosa.

As interpretações ficam mais claras se olharmos em termos dos exponenciais das estimativas:

Tabela 11- Exponenciais das estimativas

\begin{tabular}{ll}
\hline Variáveis & $\boldsymbol{e}$ \\
\hline Sexo (Masculino) & 0,42 \\
Idade & 1,02 \\
Etnia (Amarela) & 0,64 \\
Etnia (Indígena) & 0,84 \\
Etnia (Parda) & 0,97 \\
Etnia (Negra) & 0,98 \\
Localização (Rural) & 1,01 \\
Renda Familiar & 1,00 \\
\hline
\end{tabular}

A categoria de referência da variável de sexo é o gênero feminino, logo, o valor de 0,42 do primeiro coeficiente significa que sendo homem, o indivíduo tem 0,42 vezes a chance de uma mulher de passar de uma categoria com menor frequência para uma com maior frequência. Ou seja, com relação a uma mulher, o risco de ter uma frequência maior é para as mulheres. Esta interpretação pode ser estendida para uma interpretação mais ampla na variável não categorizada. Por exemplo, poderíamos dizer que ser mulher implica uma frequência religiosa maior, pois as taxas de transições de uma categoria com menor frequência para maior frequência religiosa para elas são mais rápidas do que as dos homens (significativo para $\alpha=5 \%$ ).

Para a variável de idade, o coeficiente significa que a cada aumento de um ano de idade, o risco de passar de uma categoria com menor frequência religiosa para uma de maior frequência religiosa aumenta em $1-1,02=0,02$. Simplificando: a medida em que as pessoas envelhecem, maiores se tornam suas frequências religiosas (signifi- 
cativo para $\alpha=5 \%)$. Para as variáveis Etnia e Localização, as interpretações dos coeficientes são análogas às interpretações da variável sexo. Porém, com as categorias de referência sendo Branca e Urbana, respectivamente (todos os coeficientes não significativos para $\alpha=$ $5 \%)$. Esta não significância dos coeficientes de etnia foi contrária às suposições comentadas na seção 2 . A interpretação da última variável de renda familiar é análoga à interpretação da variável Idade. Para o aumento de uma unidade de real na renda familiar, o risco de aumentar a categoria diminui em aproximadamente $1-0,9999$ $=0,0001$. Ou seja, renda familiar e frequência religiosa estão inversamente relacionadas. O sinal negativo da estimativa do coeficiente do modelo estimado ilustra que quanto maior a renda, menor a frequência religiosa (significativo para $\alpha=5 \%$ ). O valor absoluto deste coeficiente é intrigante no sentido de ser muito pequeno, apesar de o erro padrão ser, também, muito pequeno, o que resulta um valor significativo. Uma possível explicação para este valor seria a possível subestimação da renda fornecida pelos respondentes da pesquisa, tendo em vista que a renda é autodeclarada. Isso afeta a qualidade da informação desta variável estudada. Além disto, não é informada a renda do trabalho na pesquisa, apenas a renda total, individual e familiar.

\section{Considerações Finais}

O modelo de Azzi e Ehrenberg (1975) foi aquele que primeiro incorporou, formalmente, os conceitos do modelo de produção doméstica de Becker $(1964,1965)$ para explicar o comportamento religioso. Os resultados empíricos dos diversos trabalhos que buscaram testar as hipóteses do modelo de Azzi e Ehrenberg são divergentes, em que uma parte dos testes confirma as hipóteses do modelo e outra parte não confirma.

Como resultado dos testes realizados para o Brasil, as variáveis sexo, idade e renda se mostraram significativas e dependentes da variável frequência religiosa. Já as variáveis cor (etnia) e localização se mostraram não significativas. Ainda de acordo com os resultados obtidos, indivíduos do sexo feminino tendem a frequentar mais serviços religiosos. Verificou-se que a frequência religiosa também aumenta com a idade. Esses dois resultados estão de acordo com duas hipóteses do modelo de Azzi e Ehrenberg relacionando a frequência 
religiosa ao gênero e à idade. Já a renda teve uma influência negativa, ainda que de forma tênue, sobre a frequência religiosa, o que contraria a respectiva hipótese do modelo de Azzi e Ehrenberg sobre a associação entre essas duas variáveis.

\section{Referências}

ANUATTI-NETO, Francisco; NARITA, Renata Del Tedesco. A influência da opção religiosa na acumulação de capital humano: um estudo exploratório. Estudos Econômicos, São Paulo, v. 34, n. 3, julho-setembro de 2004. Disponível em $<$ http://www.scielo.br/scielo.php?script=sci arttext\&pid=S0101-41612004000300003\&lng=en\&nrm=iso $>$. Acesso em 11 Janeiro de 2013.

ASSOCIATION OF RELIGION DATA ARCHIVES (ARDA). Dados obtidos em http://www.thearda. com/internationalData/regions/profiles/Region_23_1.asp (acesso em 10/01/2013).

AZZI, C.; EHRENBERG, R. Household allocation of time and church attendance, Journal of Political Economy, v. 83, n.1, p. 27-56, 1975.

BARRO, Robert; McCLEARY, Rachel. Religion and Economic Growth Across Countries. American Sociological Review, v. 68, n.5, p.760-781, outubro de 2003.

BARROS, Carlos Pestana. A Procura de Religião em Portugal. Revista de Economia e Direito, v. 8, n.1, p.97-108, 2003.

BECKER, Gary S. Human Capital: A Theoretical and Empirical Analysis with Special Reference to Education. Nova Iorque: National Bureau of Economic Research (NBER), 1964. A Theory Allocation of Time. Economic Journal, v. 75, n.299, p. 493-517, 1965.

BERMAN, Eli; IANNACCONE, Laurence R.; RAGUSA, Giuseppe. From Empty Pews To Empty Cradles: Fertility Decline Among European Catholics. NBER WORKING PAPER SERIES. Working Paper 18350, obtido em <http://www.nber.org/papers/w18350.pdf?new_window=1> (acesso em 10/01/2013).

BRAÑAS-GARZA, Pablo. Church Attendance in Spain (1930-1992): Gender Differences and Secularization. Economics Bulletin, v.26, n. 1, p.1-9, 2004.

;NEUMAN, Shoshana. Analyzing Religiosity within an Economic Framework: The Case of Spanish Catholics, Review of Economics of the Household v.2, n.1, p. 5-22, 2004.

;NEUMAN, Shoshana. Acciones Y Creencias Religiosas: Regularidades españolas. Revista Internacional de Sociologia (RIS), v. LXVI, n.49, p.33-45, enero-abril 2008.

EHRENBERG, Ronald G. Household Allocation of Time and Church Attendance: Replication and Extension. Journal of Political Economy, v. 85, n.2, p.415-423, 1977.

HARLEY, Brian; FIREBAUGH, Glenn. American's Belief in Afterlife: Trends Over the Pasto Two Decades. Journal for the Scientific Study for Religion, v. 32, n.3, p.269-278, 1993.

HEINECK, Guido. The Determinants of Church Attendance and Religious Human Capital in Germany: Evidence from Panel Data. Discussion Paper n.263, p.1-25,Departament of Economics, University of Bamberg, Berlim, outubro de 2001.

Instituto Data Folha. $90 \%$ dos brasileiros vão à igreja, a cultos ou serviços religiosos $17 \%$ frequentam mais de uma religião. Disponível em : <http://datafolha.folha.uol.com.br/folha/datafolha/tabs/ religiao_03052007_tb4.pdf $>$ Acesso em: 10/01/2013.

LOEWENTHAL, Kate Miriam; MACLEOD, Andrew; CINNIRELA, Marco. Are Women More Religious Than Men? Gender Differences in Religious Among Different Religious Groups in the UK. Personality and Individual Differences, v.32, p.133-139, 2002. 
LONG, Stephen H; SETTLE, Rusell F. Household Allocation of Time and Church Attendance: Some Additional Evidence. The Journal of Political Economy, v. 85, n.2, p. 409-413, abril de 1997.

NEUMAN, Shoshana. Religious Observance within a Human Capital Framework: Theory and Application. Applied Economics, v.18, n.11, p. 1193-202, 1986.

OLIVEIRA, Lívio Luiz Soares de; CORTES, Renan Xavier; BALBINOTTO NETO, Giácomo. A economia da religião e seus fundamentos: teste de um modelo de escolha religiosa. Estudos Econômicos, vol.41, n.4, outubro-dezembro de 2011, pp. 811-840. Disponível em: <http://www.scielo.br/scielo. php?pid=S0101-41612011000400006\&script=sci_arttext $>$. Acesso em 22-02-2013.

PESQUISA Social Brasileira (PESB). Disponível sob consulta em: $<$ http://www.cpdoc.fgv.br/fgvopiniao/>. Acesso em: 26/03/2009).

SMITH, Adam. An Inquiry Into The Nature And Causes Of The Wealth Of Nations. The Glasgow Edition of The Works and Correspondence of Adam Smith (1981), The Online Library Of Liberty, 2004. 2 v

. Riqueza das Nações: Uma Investigação Sobre Suas Naturezas e Suas Causas, São Paulo: Editora Nova Cultural Ltda. Coleção os Economistas, 1996. 871p. 2 v.

STOLZEMBERG, Ross; BLAIR-LOY; WAITE, Linda J. Religious Participation in Early Adutlhood: Age and Life Cicle Effects on Church Membership. American Sociological Review, v.60, n.1, p.84-103, fevereiro de 1995.

SULLIVAN, Dennis H. Simultaneous Determination of Church Contributions and Church Attendance. Economic Inquiry, v.23, n.2, p. 309-20, 1985.

ULBRICH, Holley; WALLACE, Myles. Church Attendance, Age, and Belief in the Afterlife: Some Additional Evidence. Atlantic Economic Journal., v. 11, n.2, p. 44-51, 1983.

. Women's Work Force Status and Church Attendance. Journal for the Scientific Study of Religion, v. 23, n.4, p. 341-50, 1984. 